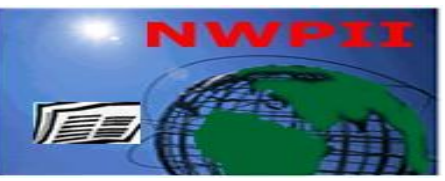

American Journal of Biomedical Sciences

ISSN: 1937-9080

nwpii.com/ajbms

\title{
Combined Effect of Low Magnesium and High Sucrose Diet on Magnesium Status and Nitric Oxide Production in Rats
}

\author{
D. P. Chaudhary ${ }^{1 *}$, Rajeshwar Sharma ${ }^{2}$ and D. D. Bansal ${ }^{2}$
}

${ }^{1}$ Directorate of Maize Research, Pusa Campus, New Delhi, India

${ }^{2}$ Department of Biochemistry, Panjab University, Chandigarh, India

*Corresponding Author:

DP Chaudhary

Senior Scientist (Biochemistry)

Directorate of Maize Research

Pusa Campus

New Delhi, India

Ph. 91-11-25842372

Fax. 91-11-25848195

E-mail: chaudharydp@gmail.com

Received:9 November 2010; | Revised: 27 December 2010; | Accepted: 16 July 2012

\begin{abstract}
Dietary magnesium deficiency as well as excess sucrose has been shown to be associated with the generation of reactive oxygen species (ROS). Nitric oxide (NO) and induction of nitric oxide synthase (NOS) are two important markers of nitrosative stress. The present study was planned to investigate the effect of low magnesium diet on magnesium status and nitric oxide production in sucrose fed rats. Male Wistar rats were divided into two groups: a control group (C); and high sucrose low magnesium diet group (HSLM). These animals were studied longitudinally over a period of three months. The urine magnesium excretion exhibited a significant decline in HSLM group. Tissue magnesium profile of various organs revealed that whereas, the magnesium content of liver, muscle and heart showed a significant decrease in the HSLM group, the magnesium content of kidneys, however, exhibit a reverse trend by showing an increase in the HSLM groups. The biochemical analysis showed a significant increase in the plasma nitrite as well as citrulline levels in the HSLM groups. These findings suggest that high sucrose and low magnesium diet may cause nitrosative stress in rats as reflected by increased production of nitric oxide and nitric oxide synthase activity.
\end{abstract}

Keywords: Magnesium, Sucrose, NO, NOS. 


\section{Introduction}

In recent years, a great volume of research has been diverted towards exploring the association between dietary manipulation of magnesium as well as sucrose and the development of reactive oxygen species (ROS). Reactive oxygen species are important mediators of cellular injury via damage to membranes or alterations of enzyme activity. The poly-unsaturated fatty acids of the membranes and of the lipoprotein particles are particularly susceptible to free radical attack, ultimately forming lipid hydroperoxides, lipid peroxides, hydrocarbons and aldehydes as their stable degradative products; these are implicated in many pathologies such as atherosclerosis, ageing, cancer, diabetes etc. [1]. High sucrose intake was reported to be an important factor contributing towards generation of ROS. It was reported that short term consumption of sucrose rich diet has a pro oxidant effect in rats [2]. Faure et al. [3] reported that the fructose component of the sucrose diet has a deleterious effect on the antioxidant defense system. Similarly sucrose feeding has been shown to cause reduced antioxidant defense in rats [4]. Reduced levels of nonenzymatic low molecular weight anti-oxidants were observed in high sucrose diet fed rats [5]. Furthermore, it was recently reported that high fat and high sucrose diet causes substantial hyperglycemia and hyperlipidemia in rats [6] which may be considered responsible for contributing towards the development of oxidative stress.

Low magnesium intake is considered to be another important factor responsible for the development of nitrosative stress. Rock and coworkers [7] demonstrated that nitric oxide concentration is markedly increased in the plasma of magnesium deficient rats. Animal models of magnesium deficiency have demonstrated a systemic pro-inflammatory, pro-oxidant state, involving multiple tissues/organs including neuronal, hematopoitic, cardiovascular, and gastrointestinal systems; during later stages of magnesium deficiency [8]. Long term chronic magnesium deficiency led to oxidative stress, apoptosis and an acceleration of aging in rat liver [9]. Wolf and colleagues [10] have recently investigated the effect of low magnesium on oxidative stress in human endothelial cells in-vitro and reported that magnesium deficiency has a prooxidant effect.

Nitric oxide is relatively harmless, but along with superoxide radical becomes precursor of many toxic species, such as peroxy and hydroxyl radicals, hydrogen peroxide, and peroxynitrite. Recently, White and colleagues have reviewed the effects of nitrosative modifications of protein and lipid signaling molecules by reactive nitrogen species [11]. We have already reported that feeding of a high sucrose low magnesium diet to male Wistar rats for a period of three months produced substantial oxidative stress in rats [12]. In the present study we have investigated the effect of low magnesium high sucrose diet on magnesium status, production of nitric oxide and its potential implication in induction of nitrosative stress in rats.

\section{Materials and Methods}

Chemicals: Methyl thymol blue (MTB), poly vinyl pyrollidine (PVP), ethylene glycol tetra acetic acid (EGTA) were from Sigma Chemical Company, St. Louis, Mo. USA and were kindly provided by Prof. Ronal R. MacGregor, Department of Anatomy and Cell Biology, University of Kansas Medical Centre, Kansas City, Kansas, USA. All other chemical used were of analytical reagent grade.

Animals and Diet: Male Wistar rats each weighing approximately $130 \mathrm{~g}$ were procured from Central Animal House, Panjab University, Chandigarh. The animals were kept in polypropylene cages under controlled conditions of temperature and light. Rats were randomly divided into two groups of six animals each and fed the respective diets for a period of three months. Control group animals were fed a control diet and high sucrose low magnesium diet group (HSLM) rats were fed a low magnesium high sucrose diet. Diet compositions are shown in Table 1. Rats were given feed in small metal dishes just before the beginning of dark cycle. Any spillage was collected in the morning and its weight equivalent was added to the following day's feed. Diets were freshly made every 3-4 
days and stored at $4{ }^{\circ} \mathrm{C}$. The rats were allowed free assess to deionized water to avoid consumption of magnesium from normal drinking water.

Sample Preparation: Rats were fasted overnight and blood samples were drawn every month from the orbital sinus of the eye under ether anesthesia. Plasma was collected immediately and estimations of nitrite and citrulline were executed. At the end of three months of feeding experimental diets, the animals were killed by exsanguinations from heart under diethyl ether anesthesia. The tissues namely liver, kidney, heart and thigh muscle were removed immediately and washed thrice with $0.9 \% \mathrm{NaCl}$. Tissues were blotted, weighed and digested completely with 5.0 $\mathrm{ml}$ of digestion mixture $\left(\mathrm{HNO}_{3}: \mathrm{HClO}_{4} ; 3: 1\right)$. The magnesium content was then estimated in the digestion mixture. For the estimation of urine magnesium status, 24 hour urine of the animals is collected and mixed thoroughly.

Table 1. Composition of the experimental diets.

\begin{tabular}{lcc}
\hline $\begin{array}{l}\text { Ingredients } \\
\text { (g/kg diet) }\end{array}$ & Control & $\begin{array}{c}\text { High Sucrose } \\
\text { Low Magnesium (HSLM) }\end{array}$ \\
Starch & 650 & - \\
Sucrose & - & 650 \\
Casein & 200 & 200 \\
Corn oil & 50 & 50 \\
Cellulose & 50 & 50 \\
Salt mixture & 35 & 35 \\
Vitamin mixture & 10 & 10 \\
DL-methionine & 3 & 3 \\
Choline chloride & 2 & 2 \\
\hline
\end{tabular}

${ }^{1}$ Salt mixture expressed in g/kg: $\mathrm{CaHPO}_{4}, 60 \mathrm{~g} ; \mathrm{KCl}, 200 \mathrm{~g} ; \mathrm{NaCl}, 120 \mathrm{~g} ; \mathrm{MgO}, 21.0 \mathrm{~g} ; \mathrm{MgSO}_{4 .} .2 \mathrm{H}_{2} \mathrm{O}, 100 \mathrm{~g} ; \mathrm{Fe}_{2} \mathrm{O}_{3}, 6 \mathrm{~g} ; \mathrm{FeSO}_{4}$. $7 \mathrm{H}_{2} \mathrm{O}, 10 \mathrm{~g}$; trace elements $10 \mathrm{~g} / \mathrm{kg}$ including $\mathrm{Mn}, 0.8 \mathrm{~g}$; CuO, $125 \mathrm{~g} ; \mathrm{Co}, 0.0009 \mathrm{~g} ; \mathrm{Zn}, 0.450 \mathrm{~g} ; \mathrm{I}, 0.0049 \mathrm{~g}$.

${ }^{2} \mathrm{~A}$ similar composition was used in all the experimental groups, except for the addition of $\mathrm{MgO}$ and $\mathrm{MgSO}_{4} \cdot 2 \mathrm{H}_{2} \mathrm{O}$ to provide (per $\mathrm{kg}) 507.0 \mathrm{mg}$ of $\mathrm{Mg}$ in the control diets and $90.0 \mathrm{mg}$ of $\mathrm{Mg}$ in the high sucrose low magnesium diets.

${ }^{3}$ Expressed per kg of the vitamin mixture: retinol, $539 \mathrm{mg}$; cholecalciferol, $6.250 \mathrm{mg}$; thiamine, $2000 \mathrm{mg}$; riboflavin, $1500 \mathrm{mg}$; niacin, $7000 \mathrm{mg}$; pyridoxine, $1000 \mathrm{mg}$; cyanocobalamine, $5 \mathrm{mg}$; ascorbic acid; $80.000 \mathrm{mg}$; D,L- $\alpha$-tocophenyl acetate, 17,000 mg; menadione, $1000 \mathrm{mg} / \mathrm{kg}$; nicotinic acid, 10,000 mg; folic acid, $500 \mathrm{mg}$; para-amino benzoic acid, $5000 \mathrm{mg}$; biotin, $30 \mathrm{mg} / \mathrm{kg}$.

Table 2. Time course evaluation of plasma nitrite and citrulline levels in the experimental animals

\begin{tabular}{lcc}
\hline Parameters & C & HSLM \\
\hline At the end of one month & & \\
\hline Nitrite $(\mu \mathrm{mol} / \mathrm{L})$ & $3.27 \pm 0.15$ & $4.43 \pm 0.20^{* * *}$ \\
Citrulline $(\mu \mathrm{mol} / \mathrm{L})$ & $8.70 \pm 0.92$ & $17.45 \pm 1.85^{* * *}$ \\
At the end of two months & & \\
Nitrite $(\mu \mathrm{mol} / \mathrm{L})$ & $3.28 \pm 0.19$ & $4.38 \pm 0.12^{* * *}$ \\
Citrulline $(\mu \mathrm{mol} / \mathrm{L})$ & $8.69 \pm 0.97$ & $16.90 \pm 1.54^{* * *}$ \\
At the end of three months & & \\
Nitrite $(\mu \mathrm{mol} / \mathrm{L})$ & $3.21 \pm 0.19$ & $4.14 \pm 0.19^{* * *}$ \\
Citrulline $(\mu \mathrm{mol} / \mathrm{L})$ & $8.57 \pm 1.19$ & $14.45 \pm 1.10^{* * *}$ \\
\hline
\end{tabular}

Mean values with their standard deviations, $n=6$. HSLM, High Sucrose Low Magnesium 


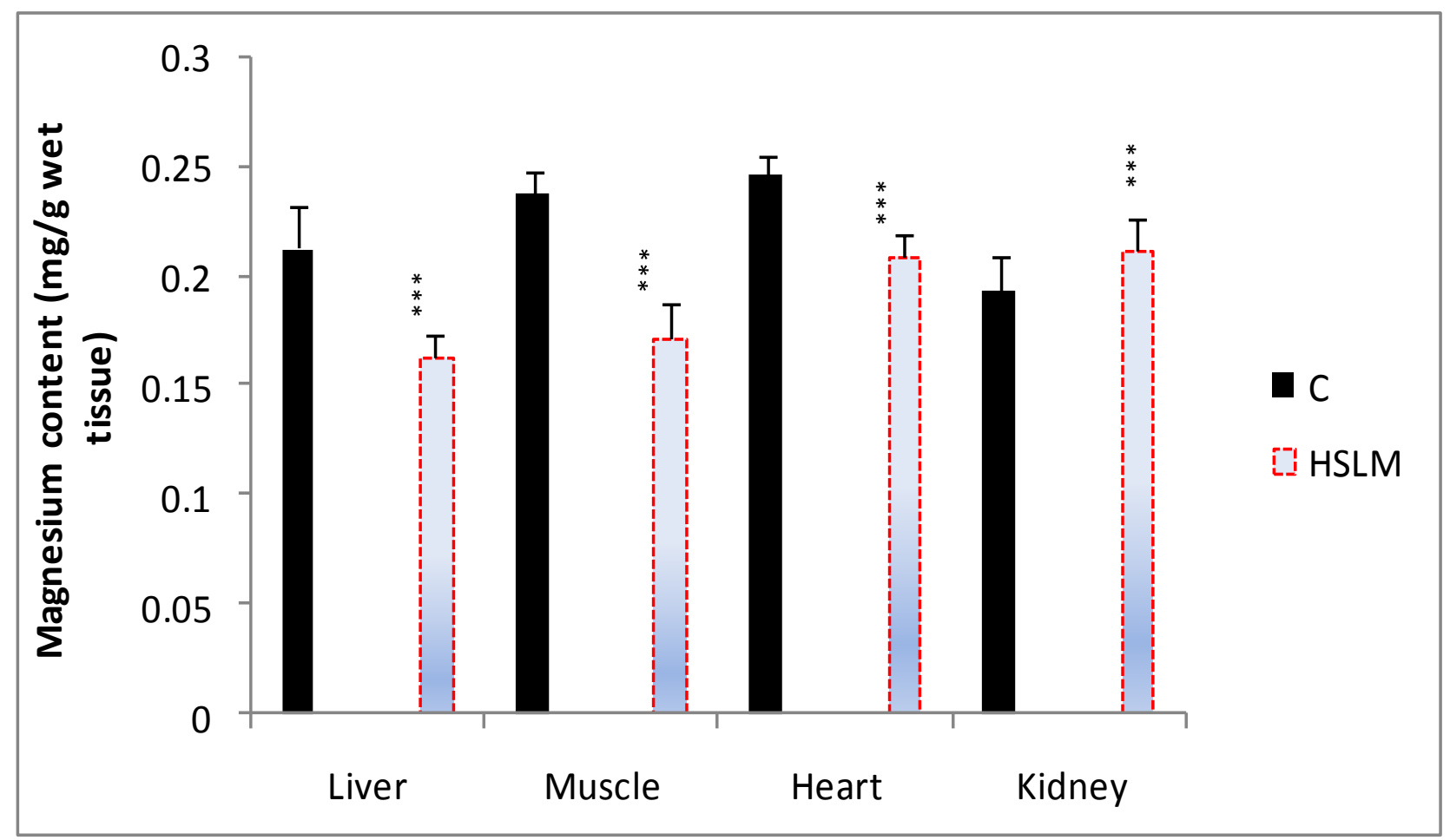

Figure 1. Magnesium content of rat tissues (mg/g wet tissue) after three months of feeding experimental diet. Mean values with their standard deviations, $\mathrm{n}=6, \mathrm{C}$, control; HSLM, high sucrose low magnesium * significantly different from control group, ${ }^{*} \mathrm{p}<0.05, * * \mathrm{P}<0.01, * * * \mathrm{P}<0.005$.

Biochemical analysis: Tissue as well urine magnesium was estimated by the modified method of Thuvasethakul \& Wajjwalku [13]. The plasma nitrite was estimated by the method of Green et al. [14]. The inducible nitric oxide synthase activity (plasma citrulline levels) was measured by the method of Boyde et al. [15].

Statistical Analysis: Statistical analysis was performed using GraphPad InStat (GraphPad Inc., San Diego, CA, USA) software package. Results were expressed as mean and SD of 6 observations in each group. Further, the statistical significance of the differences among the various dietary groups was determined by subjecting the data to one way ANOVA with diet as the main effect, followed by inspection of all differences between pairs of means by Tukey's test. Differences were considered statistically significant at $P<0.05$.

\section{Results}

Data in Table 2 presents the time course evaluation of plasma nitrite and citrulline following chronic feeding of the experimental diets. The levels of plasma nitrite in HSLM group increased significantly by the end of $1^{\text {st }}$ month of feeding the experimental diet and this elevation was maintained up to the end of $2^{\text {nd }}$ month of feeding. However, a slight decline was observed in the NO concentration after 3 months of feeding the experimental diets compared to the values observed at the end of first and second month of feeding. Almost similar results were obtained in case of plasma citrulline which showed significant increase in the HSLM group by the end of $1^{\text {st }}$ as well as $2^{\text {nd }}$ month of feeding the experimental diets and a slight decline by the end of $3^{\text {rd }}$ month of feeding. Figure 1 presents the tissue magnesium content of animals at the end of three months of feeding the experimental diets. The magnesium content of liver, thigh muscle and heart decreases significantly in HSLM group. However, kidney showed a reverse trend whereby the magnesium content was increased in the HSLM group. Figure 2 depicts the urine magnesium content $(\mathrm{mg} / 24 \mathrm{hr}$ urine) of rats after three months of feeding the experimental diets. The urine magnesium content reduced drastically in HSLM group. 


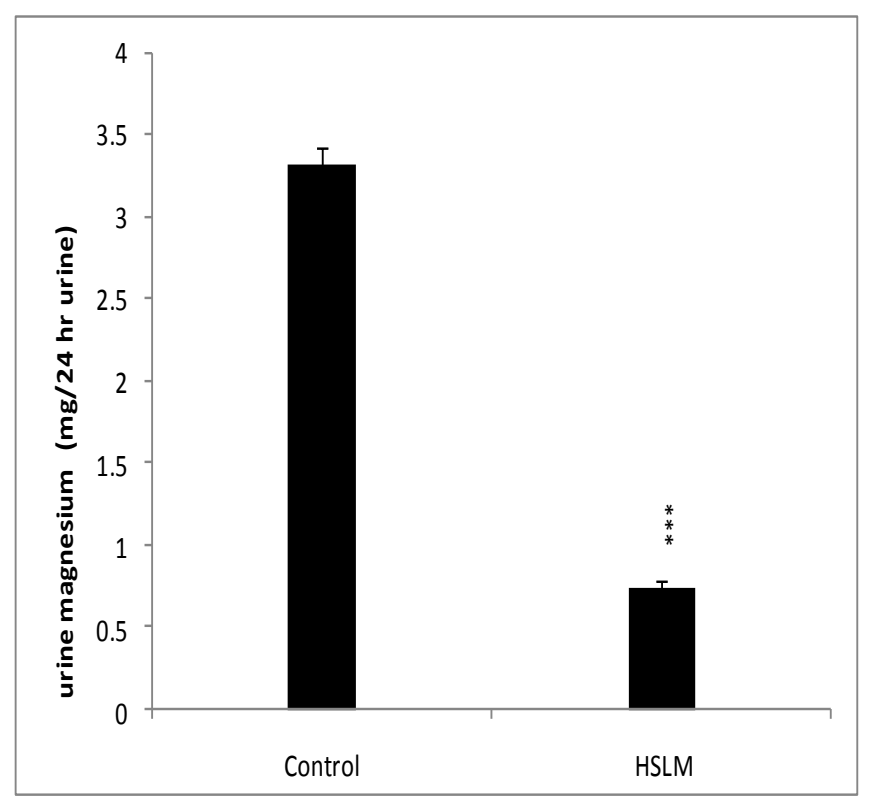

Figure 2. Urine magnesium content (mg/24 hr. urine) of rats after three months of feeding experimental diet. Mean values with their standard deviations, $\mathrm{n}=6, \mathrm{C}$, control; HSLM, high sucrose low magnesium *significantly different from control group, $* \mathrm{p}<0.05$, $* * \mathrm{P}<0.01, * * * \mathrm{P}<0.005$.

\section{Discussion}

Within the first week of feeding the experimental diets, classical signs of magnesium deficiency (including hyperemia of ears, growth retardation, hair loss and edema of paws) were observed in the HSLM group animals. The deficiency in dietary intake of magnesium was reflected by a significant reduction in urine magnesium levels in HSLM group. Urine magnesium levels are considered to be a reliable indicator of magnesium deficiency. Chutkow [16] reported negligible urinary excretion of magnesium in magnesium-depleted rats. Similar results were reported by Elin et al. [17]. Tissue magnesium profile of liver, heart and muscle demonstrate that cellular magnesium content was also decreased along with extra-cellular magnesium content indicating that hypomagnesaemia was successfully induced in the animals of HSLM group. Some earlier studies have also reported similar results. Davidson and Blackwell [18] noticed a progressive fall in magnesium content of skeletal muscle in a 62day period of magnesium deficiency in squirrel monkeys. Whang and Welt [19] found that feeding magnesium deficient diets to rats for a period of 60 days results in a decrease in muscle magnesium content. Liver magnesium was significantly reduced after 62 days of feeding magnesium deficient diet to rats [20]. Lim and Jacobs [21-23] have suggested that muscle magnesium is the most freely exchangeable and thus the first to fall during magnesium depletion. An increase in the magnesium content of kidney in magnesium deficient animals may be due to the increased reabsorption of magnesium by the loop of Henle during magnesium deficiency as it is the major site of magnesium re-absorption in the renal tubule and principal locus of renal control of magnesium excretion [24]. The cells within this loop sense the concentration of magnesium through receptors and when the serum magnesium concentration is low, kidney reabsorb magnesium, which may be the cause for higher magnesium observed in the kidney of HSLM group animals.

The nitrite is the degradative product of NO, and the enzyme nitric oxide synthase produced NO during the conversion of L-arginine to Lcitrulline. Therefore the measurement of nitrite and citrulline in rat plasma is indirectly an estimation of nitric oxide (NO) and nitric oxide synthase (NOS), respectively. Magnesium deficiency in rats leads to nitrosative stress as the concentration of $\mathrm{NO}$ is markedly increased in plasma of magnesium deficient rats [7]. Decreasing the magnesium concentrations in the culture medium from $0.39 \mathrm{mM}$ to $0.021 \mathrm{mM}$, increased NO release from alveolar macrophages for 2 hour [25]. Mak and colleagues [26] investigated the effect of dietary magnesium deficiency on NO production and its role in mediating oxidative depletion of RBC glutathione in rats. They found increased plasma nitrate plus nitrite levels during the first week on magnesium deficient diet and a subsequent RBC glutathione depletion. Maurya and Rizvi [27] have observed significant increase in NO level as a function of human age. They further reported that increased NO may contribute to the development of nitrosative stress during aging. In earlier study plasma nitrite and nitrate levels were found to be 
significantly higher in the sucrose group compared to the starch group [2]. An initial rise and a subsequent fall in the activity of NOS was observed in female fischer rats placed on a sucrose rich diet [28]. Various reactive oxygen species (ROS) viz. superoxide, hydrogen peroxide, and hydroxyl radicals can inactivate NO, For example, superoxide combines with NO to produce peroxynitrite (ONOO-), a potent cytotoxic reactive nitrogen species that subsequently reacts with protein, lipids and DNA to induce tissue damage [29]. This inactivation of NO by ROS may explain the fall in levels of NO in the animals of HSLM group after 3 months of feeding high sucrose low magnesium diet. However, NO has also been shown to be cytoprotective through its reaction with lipid radicals as well as with transition metal iron [30]. Whether NO acts as a pro oxidant or is increased in the experimental groups in response to oxidative stress needs further investigation.

\section{Conclusion}

Magnesium deficiency is common and is considered as a causative factor towards the development of nitrosative stress. Sucrose is reported to be another pro-oxidant component of the diet. Combined together, a diet high in sucrose and low in magnesium may be considered as a potential risk factor for the development of nitrosative stress and its potential implication in the development of Diabetes Mellitus and other related complications.

\section{References}

1. Yagi, K. Lipid peroxides in human diseases. Chem. Phys. Lipids, 1987, 45, 337-351. DOI:10.1016/0009-3084(87)90071-5

2. Busserolles, J.; Rock, E.; Gueux, E.; Mazur, A.; Grolier, P.; Rayssiguier, Y. Short term consumption of high sucrose diet has a prooxidant effect in rats. Br. J. Nutr., 2002, 87, 337-42. DOI: 10.1079/BJN2002524

3. Faure, P.; Rossini, E.; Lafond, J. L.; Richard, M. J.; Favier, A.; Halimi, S.; Vitamin E improves free radical defense system potential and insulin sensitivity of rats fed high fructose diet. J. Nutr., 1997, 127, 103-107.

4. Rayssiguier, Y.; Gueux, E.; Bussiere, L.; Mazur, A. Copper deficiency increases the susceptibility of lipoproteins and tissues to peroxidation in rats. J. Nutr., 1993, 123, 13431348.

5. Ryu, S.; Ornoy, A.; Samuni, A.; Zangen, S.; Kohen, R. Oxidative stress in Cohen diabetic rat model by high-sucrose, low-copper diet: inducing pancreatic damage and diabetes. Metabolism, 2008, 57, 1253-1261. DOI: 10.1016/j.metabol.2008.04.021

6. Mehra, P.; Kaul, A.; Bansal, D. D. Studies on the development of a non-genetic obese type-2 diabetic rat model: Amelioration by $(+)$ catechin hydrate. Am. J. Biomed. Sci., 2010, 2(4), 235-236. DOI: 10.5099/aj100400352

7. Rock, E.; Astier, C.; Lab, C.; Malpuech, S.; Nowacki, W.; Gueux, E.; Mazur, A.; Rayssigiuer, Y. Magnesium deficiency in rat induces a rise in plasma nitric oxide. Magnes. Res., 1995, 8, 237-242.

8. Tejero-Taldo, M. I.; Kramer, J. H.; Mak, I. T.; Komarov, A. M.; Weglicki, W. B. The nerveheart connection in the pro-oxidant response to Mg-deficiency. Heart Fail. Rev., 2006, 11, 35 44. DOI: 10.1007/s10741-006-9191-7

9. Martin, H.; Uring-Lambert, B.; Adrian, M.; Lahlou, A.; Bonet, A.; Demougeot, C.; Devaux, S.; Lurant, P.; Richert, L.; Berthelot A. Effects of long-term dietary intake of magnesium on oxidative stress, apoptosis and ageing in rat liver. Magnes. Res., 2008, 21, 124-130. DOI : 10.1684/mrh.2008.0139

10. Wolf, F. I.; Trapani, V.; Simonacci, M.; Ferré, S.; Maier, J. A. Magnesium deficiency and endothelial dysfunction: is oxidative stress involved? Magnes. Res., 2008, 21, 58-64. DOI $:$ 10.1684/mrh.2008.0129

11. White, P. J.; Charbonneau, A.; Cooney, G. J., Marette, A. Nitrosative modifications of protein and lipid signaling molecules by reactive nitrogen species. Am $J$ Physiol Endocrinol Metab. 2010, 299, E868-878. DOI: 10.1152/ajpendo.00510.2010

12. Chaudhary, D. P.; Boparai, R. K.; Bansal, D. D. Implications of oxidative stress in high sucrose low magnesium diet fed rats. Eur. J. 
Nur., $\quad 2007, \quad \mathbf{4 6}, \quad 383-390 . \quad$ DOI: 10.1007/s00394-007-0677-4

13. Thuvasethakul, P.; Wajjwalku, W. Serum magnesium determined by use of methyl thymol blue. Clin. Chem., 1987, 33, 614-615.

14. Green, L. C.; Wagner, D. A.; Glogowski, J.; Skipper, P. L.; Wishnok, J. S.; Tannenbaum, S. R. Analysis of nitrate, nitrite and $\left[{ }^{15} \mathrm{~N}\right]$ nitrate in biological fluids. Anal. Biochemistry, 1982, 126, 131-138. DOI: 10.1016/00032697(82)90118-X

15. Boyde, T. R.; Rahmatullah, M. Optimization of conditions for colorimetric determination of citrulline using diacetyl monooxime. Anal. Biochem., 1980, 107, 424-431. DOI: 10.1016/0003-2697(80)90404-2

16. Chutkow, J. G. Studies on the metabolism of magnesium in the magnesium deficient rats. $J$. Lab. Clin. Med., 1965, 65, 912-926.

17. Elin, R. J.; Armstrong, W. D.; Singer, L. Body fluids electrolyte composition of chronically magnesium deficient and control rats. Am. $J$. Physiol., 1971, 220, 543-548.

18. Davidson, I. W.; Blackwell, W. L. Changes in carbohydrate metabolism of squirrel monkeys with chromium dietary supplementation. Proc. Soc. Expt. Biol. Med., 1968, 127, 66-72.

19. Whang, R.; Welt, L. G. Observations in experimental magnesium depletion. J. Clin. Invest., $\quad 1963, \quad \mathbf{4 2}, \quad 305-313 . \quad$ DOI: 10.1172/JCI104717

20. Martindale, L.; Heaton, F. W. Magnesium deficiency in the adult rat. Biochem. J., 1964, 92, 119-126.

21. Lim, P.; Jacob, E. Magnesium status in chronic uremic patients. Nephron., 1972, 9, 300-307. DOI: 10.1159/000180161

22. Lim, P.; Jacob, E. Magnesium deficiency in liver cirhossis. Q. J. Med., 1972, 41, 291-300.

23. Lim, P.; Jacob, E. Tissue magnesium levels in chronic diarrhea. J. Lab. Clin. Med., 1972, 80, 313-321.

24. Dirks, J. H. The kidney and magnesium regulation. Kid. Int., 1983, 23, 771-777. DOI: 10.1038/ki.1983.93

25. Yokoyama, T.; Oono, H.; Miyamoto, A.; Ishiguro, S.; Nishio, A. Magnesium deficient medium enhances NO production in alveolar macrophages isolated from rats. Life Sci., 2003, 72, 1247-1257. DOI: 10.1016/S00243205(02)02371-8

26. Mak, I. T.; Komarov, A. M.; Wagner, T. L.; Stafford, R. E.; Dickens, B. F.; Weglicky, W. B. Enhanced $\mathrm{NO}$ production during $\mathrm{Mg}$ deficiency and its role in mediating red blood cell glutathione loss. Am. J. Physiol., 1996, 271, C385-C390.

27. Maurya, P. K.; Rizvi, S. I. Alterations in plasma nitric oxide during aging in humans. Indian J. Biochem. Biophys., 2009, 46, 130132.

28. Roberts, K. C.; Vaziri, N. D.; Wang, X. Q.; Barnard, R. J. Enhanced NO inactivation and hypertension induced by a high fat, refined carbohydrate diet. Hypertension, 2000, 36, 423-429. DOI: 10.1161/01.HYP.36.3.423

29. Halliwel, B. What nitrates tyrosine? Is nitrotyrosine specific as a biomarker of peroxinitrite formation in-vivo? FEBS Lett., 1997, 411, 157-160. DOI: 10.1016/S00145793(97)00469-9

30. Joshi, M. S.; Ponthier, J. L.; Lancaster, J. R. Cellular antioxidants and pro-oxidants action of nitric oxide. Free Rad. Biol. Med., 1999, 27, 1357-1360. DOI: $\quad 10.1016 / \mathrm{S} 0891-$ 5849(99)00179-3 